$\begin{array}{cl}\begin{array}{cl}\text { Revue } \\ \text { de /histoire } \\ \text { des religions }\end{array} & \text { Revue de l'histoire des religions } \\ & \begin{array}{c}4 \mid 2009 \\ \text { Varia }\end{array}\end{array}$

\title{
Rationalisme et théologie dans le monde musulman médiéval
}

Bref état des lieux

Rationalism and Theology in the Medieval Muslim World

Mohammad Ali Amir-Moezzi et Sabine Schmidtke

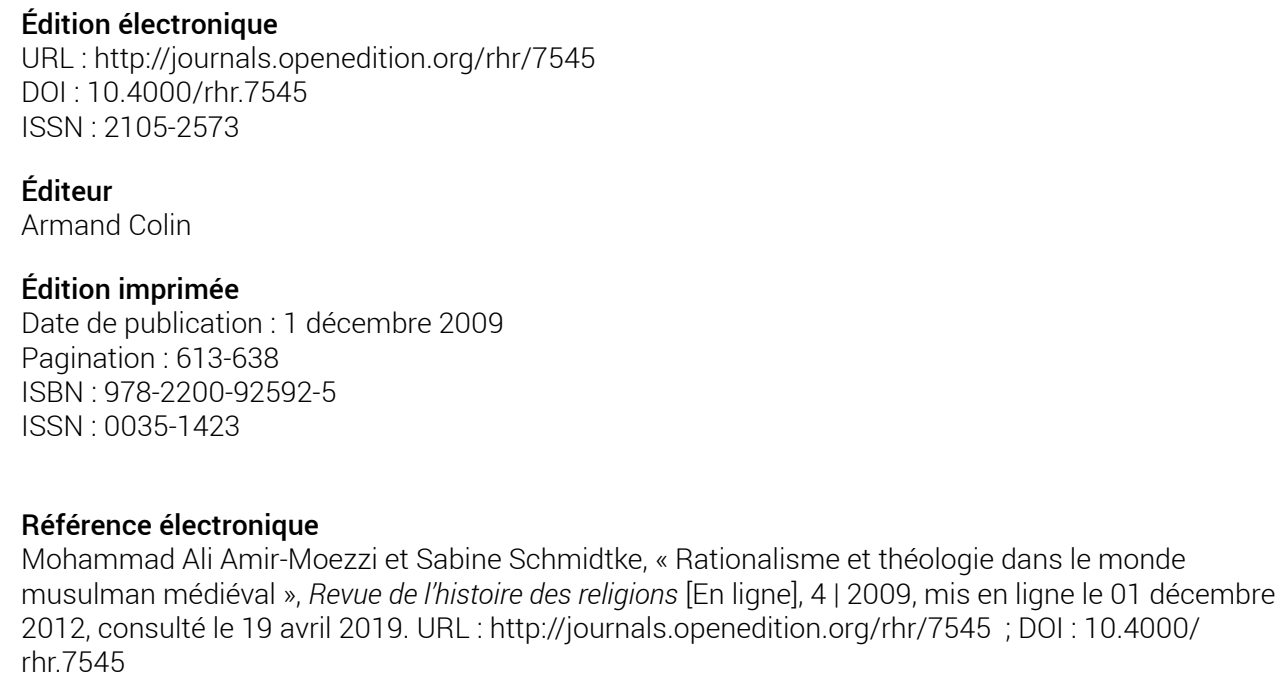

\section{Éditeur}

Armand Colin

Édition imprimée

Date de publication : 1 décembre 2009

Pagination : 613-638

ISBN : 978-2200-92592-5

ISSN : 0035-1423

\section{Référence électronique}

Mohammad Ali Amir-Moezzi et Sabine Schmidtke, «Rationalisme et théologie dans le monde

musulman médiéval », Revue de l'histoire des religions [En ligne], 4 | 2009, mis en ligne le 01 décembre

2012, consulté le 19 avril 2019. URL : http://journals.openedition.org/rhr/7545; DOI : 10.4000/ rhr.7545 
MOHAMMAD ALI AMIR-MOEZZI

École Pratique des Hautes Études, Paris

SABINE SCHMIDTKE

Freie Universität Berlin

\section{Rationalisme et théologie dans le monde musulman médiéval Bref état des lieux}

L'article est un bref bilan bibliographique des sources et des travaux concernant la théologie rationaliste dans le monde musulman au Moyen-Âge (grosso modo du $8^{e}$ au $15^{e}$ siècle de l'ère commune). Les principales Ecoles de la théologie spéculative scolastique, surtout le Mu'tazilisme et l'Ash'arisme, ainsi que les plus importantes étapes des études islamologiques sur ces Écoles sont examinées. Une attention particulière est accordée à la constante circulation des idées non seulement entre divers courants de l'islam (par exemple les différentes branches $d u$ shi 'isme), mais aussi avec ceux du judaïsme et du christianisme. La nécessité grandissante de l'examen transversal des systèmes théologiques rationalistes des trois monothéismes est également soulignée.

\section{Rationalism and Theology in the Medieval Muslim World}

The article provides a survey of rational theology in the medieval world of Islam (8th through 15th centuries CE) and the current state of scholarship. It discusses the most important strands of thought, viz. Mu'tazilism and Ash'arism, as well as the main stages of their scholarly investigation. Particular attention is given to the reception of the various strands not only within Islam (especially among Shīites), but also among Jews and Christians, and the growing significance of research transcending religious boundaries is emphasized. 
Le rationalisme, dans le sens de recours à la raison logique et à la rhétorique dialectique, a été un élément caractéristique de la pensée théologique islamique depuis les temps les plus anciens. Au-delà de la discussion sur l'authenticité et donc la datation d'un certain nombre de sources, nous disposons d'un petit corpus de textes très anciens d'authenticité certaine où des points doctrinaux concernant l'opposition entre le libre arbitre et le déterminisme sont discutés de manière dialectique. L'usage de ce genre d'argumentation dans des écrits aussi anciens prouve l'usage de la raison logique dans la rhétorique religieuse islamique dès les premiers temps de l'islam (von Grunebaum 1970. Cook 1980; 1981. van Ess 1975; 1977), usage qui atteignit son apogée entre le $9^{\mathrm{e}}$ et le $11^{\mathrm{e}}$ siècle (Nagel 1988. Endress 1997). Il est vrai que le rationalisme a toujours eu de puissants adversaires à travers l'histoire de l'islam, mais il a constamment continué d'être l'un des principaux courants de la pensée théologique, et on peut dire que c'est seulement sous la pression du renouveau du fondamentalisme islamique moderne qu'il a été marginalisé et maltraité comme jamais auparavant.

\section{Courants Mu'tazilites et Shi'ites}

Les Mu'tazilites ont constitué la plus ancienne «École » de la théologie rationaliste islamique (théologie scolastique spéculative

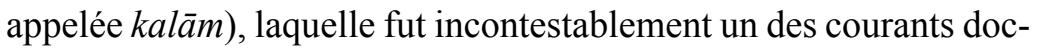
trinaux les plus influents de la pensée en islam. Les Mu'tazilites, professant la primauté de la raison humaine et du libre arbitre (opposé à la prédestination), développèrent une épistémologie, une ontologie et une psychologie qui constituèrent les bases de leurs spéculations sur la nature de l'univers, de Dieu, de l'homme et du phénomène religieux en tant que Révélation et Loi divines. Dans leur doctrine éthique, les Mu'tazilites soutenaient que le Bien et le Mal ne peuvent être appréhendés qu'à travers l'exercice de la raison humaine. Grâce à leur épistémologie spécifique, ils purent élaborer une méthodologie juridique d'une très haute complexité.

Les origines du mu'tazilisme remontent au $8^{\mathrm{e}}$ siècle de l'ère commune et la période classique de son développement s'étend de 
la seconde moitié du $9^{\mathrm{e}}$ jusqu'au milieu du $11^{\mathrm{e}}$ siècle. Devenu un moment doctrine d'État comme théologie « officielle» du califat abbasside au $9^{\mathrm{e}}$ siècle, il se divisa au tournant du $10^{\mathrm{e}}$ siècle en deux principales Écoles, celle de Bagdad et celle de Bașra (Bassorah). Ses figures dominantes furent Abū 'Alī al-Jubbā'̄i (m. 916) et son fils Abū Hāshim (m. 933). Les disciples de celui-ci formèrent un important courant connu sous le nom de Bahshamiyya. Parmi les nombreux adeptes de ce courant, nous pouvons mentionner l'élève d'Abū Hāshim, Abū 'Alī b. Khallād (m. ca. 961), et les étudiants de ce dernier, Abū 'Abdallāh al-Bașrī (m. 980) ou encore Abū Ishāa b. 'Ayyāsh. Le grand juge 'Abd al-Jabbār al-Hamadhān̄̄ (m. 1025), élève d'Abū 'Abdallāh et d'Abū Isḥāq, fut un auteur prolifique. Un étudiant de 'Abd al-Jabbār, Abū 1-Husayn al-Bașrī (m. 1044) mit sur pied ce qui peut être considéré comme une des dernières Écoles de pensée créatives du mu'tazilisme. Après lui, le mouvement commença lentement son déclin dans l'islam sunnite pour disparaître en tant que tel au $14^{\mathrm{e}}$ siècle. Cependant son influence est restée très forte dans l'islam shi'ite durant tout le Moyen Âge, les temps modernes et même jusqu'à nos jours. Il est vrai que les spéculations théologiques dialectiques sont très anciennes parmi les Shi'ites, toutes tendances confondues. Elles se rencontrent dès le $8^{\mathrm{e}}$ siècle dans les fragments remontant aux penseurs tels que Hishām b. al-Hakam ou Zurāra b. A'yan ou encore aux confins des $9^{\mathrm{e}}$ et $10^{\mathrm{e}}$ siècles chez des théologiens-juristes comme Ibn Abī 'Aqīl al-Nu'mānī ou Ibn Qiba al-Rāzī (Modarressi 1993). La connexion décisive entre mu'tazilisme et shi' isme eut lieu aux $10^{\mathrm{e}}$ et $11^{\mathrm{e}}$ siècles, notamment dans l'entourage du savant imamite al-Shaykh al-Mufîd (m. 1022) et ses disciples directs et indirects tels al-Sharīf al-Murtadāa (m. 1044) et Abū Ja ‘far al-Ṭūsī (m. 1068) (Mc Dermott 1978. Amir-Moezzi 1992, introduction). L'imprégnation du shi'isme, notamment le shi'isme duodécimain, par le mu'tazilisme fut si profonde que même après la disparition des $\mathrm{Mu}$ 'tazilites proprement dits, leur pensée continua à se développer dans la tradition duodécimaine " rationaliste théologico-juridique » et ce jusqu'à nos jours (Madelung 1970. Amir-Moezzi 1993).

Ajoutons enfin que la recherche contemporaine, depuis le début du $20^{\mathrm{e}}$ siècle, fit découvrir une réminiscence sunnite de la conception mu'tazilite du rationalisme, laquelle trouve son expression dans ce qui est appelé « le Néo-mu'tazilisme », terme vague dési- 
gnant diverses tendances de penseurs musulmans qui, en s'appuyant

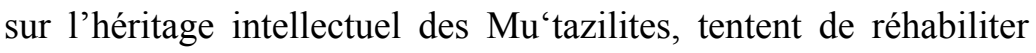
l'application du rationalisme dans le discours islamique moderne (Hildebrandt 2007. al-Mas'ūdī 2008).

\section{LeS ASH'ARITES}

En deuxième lieu, pour ce qui est l'usage du rationalisme, il convient de mentionner l'École théologique des Ash 'arites, tirant son nom du fondateur éponyme Abū 1-Hasan al-Ash 'arī (m. 935) qui fut à l'origine disciple du maître mu'tazilite Abū 'Alī alJubbā'̄̄. Vers l'âge de quarante ans, al-Ash'arī abandonna les enseignements mu'tazilites pour élaborer son propre système doctrinal. Lui et ses disciples essayèrent de constituer une via media entre les deux principales tendances théologico-doctrinales de l'époque, à savoir le mu'tazilisme et le traditionalisme hanbalite. Méthodologiquement, les Ash'arites appliquaient l'argumentation rationnelle dans leurs doctrines et écrits théologiques, comme ce

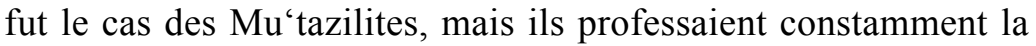
supériorité de la Révélation sur la raison. Sur le plan doctrinal, ils opposaient leur subjectivisme éthique à l'objectivisme éthique du mu'tazilisme et élaborèrent la notion de "l'acquisition humaine " (kasb) comme une voie médiane entre le libre arbitre mu'tazilite et le prédéterminisme radical des traditionalistes. Sur ces bases, l'ash'arisme développa ses propres positions théologiques. Comme cela caractérise toute évolution de la pensée théologique en islam, al-Ash 'arī adopta et adapta dans son propre système bon nombre de concepts formulés par les penseurs antérieurs (Perler \& Rudolph 2000). En guise d'exemple, on peut citer Ibn Kullāb (m. 855 ?) qui avait déjà tenté de combiner la méthodologie rationnelle des Mu'tazilites avec les positions doctrinales des traditionalistes sunnites ou encore Dirār b. 'Amr (m. 796) qui a été le premier à formuler de manière dialectique la notion d'" acquisition humaine ». Cependant, avec le succès progressif de l'École ash'arite ces anciens prédécesseurs furent bientôt oubliés.

Vers la fin du $10^{\mathrm{e}}$ siècle, l'ash'arisme s'était déjà établi comme une des principales Écoles théologiques dans les régions centrales des terres d'islam, surtout grâce à l'éminent théologien et juge mālikite 
Abū Bakr al-Bāqillānī (m. 1013) qui jouissait de la protection du vizir shi' ite bouyide al-Ṣāhịib b. 'Abbād (m. 995), comme cela a été également le cas de son contemporain mu'tazilite 'Abd al-Jabbār al-Hamadhānī. Ce fut également grâce aux deux disciples d'alBāqillānī, Abū Bakr Muhammad b. al-Ḥasan Ibn Fūrak (m. 1015) et Abū Isḥāq al-Isfarā'inī (m. 1020), qui enseignaient à Rayy et à Nīshāpūr, que l'ash'arisme se répandit en Iran où beaucoup d'autres grands penseurs ash'arites de la génération suivante se firent remarquer. De l'autre côté des terres musulmanes, en Afrique du Nord, les écrits théologiques d'al-Bāqillān̄̄ connurent une popularité certaine surtout grâce à la diffusion de l'École juridique mālikite et c'est précisément là que les fragments de son opus magnum, le Kitāb Hidāyat al-mustarshidīn, ont été préservés sous forme manuscrite. L'ash'arisme atteignit son apogée durant la première période seljoukide sous le patronat du puissant vizir iranien Niẓām al-Mulk (m. 1099) et devint la doctrine fondamentale du réseau des universités théologiques Nizāamiyya. Les plus influents théologiens ash'arites de cette époque furent Abū Bakr Aḥmad b. Muḥammad b. Muhammad al-Fūrakī (m. 1085) et le célèbre Imām al-Ḥaramayn Abū l-Ma'ālī al-Juwaynī (m. 1085). Comme ce fut le cas d'Abū lHusayn al-Bașrī parmi les Mu'tazilites, al-Juwaynī fut le premier à introduire les méthodes et les notions philosophiques dans le kalām ash'arite, et pour cause, il avait longuement étudié et a été profondément influencé par les ouvrages d'Abū 1-Husayn (Madelung 2006). Avec al-Juwaynī la phase ancienne de l'ash'arisme prit fin. La phase suivante fut caractérisée par une pénétration massive de la méthodologie et de la pensée théologique ash'arite par la philosophie et la logique. Cette seconde étape fut inaugurée par Abū Hāàmid al-Ghazālī (m. 1111) et compta parmi ses auteurs les plus décisifs Muhammad b. 'Abd al-Karīm al-Shahrastān̄̄ (m. 1153, qui semble avoir été en même temps un crypto-shi'ite ismaélien) et Fakhr al-Dīn al-Rāzī (m. 1209). Dans les contrées orientales de l'islam, l'ash 'arisme demeura un des courants les plus importants de la pensée jusqu'à la fin du $16^{\mathrm{e}}$ siècle. Dans le sunnisme, il eut plus de succès et une vie beaucoup plus longue que le mu'tazilisme, quoique, tout comme celui-ci, il eût constamment à affronter l'adversité anti-rationaliste des milieux traditionalistes.

Les différents courants de la théologie rationnelle musulmane furent solidement liés les uns aux autres - et ce malgré leurs nom- 
breuses divergences - et n'ont jamais cessé de se déterminer les uns par rapport aux autres dans un continuel processus d'interaction et d'interpénétration. Ceci est également vrai pour d'autres Écoles, moins représentées dans les régions les plus centrales du monde musulman, comme le māturīdisme (nommé selon le théologien Abū Manșūr al-Māturīdī, m. 944), solidement ancré dans les positions traditionalistes hanafites d'une part et dans la pensée mu'tazilite d'autre part. Étant installée dans les pays périphériques de l'islam, en l'occurrence à l'extrême Nord-Est de l'Iran, en Transoxiane, cette École théologique eut une influence beaucoup plus limitée que les deux précédentes, sauf plus tard sur les terres centrales de l'empire ottoman (Rudolph 1997. Badeen 2008).

\section{Circulations des idées entre Islam et aUtres Religions}

Ce qui a été dit au sujet de l'interaction constante entre différentes tendances de la pensée islamique est tout aussi vrai en ce qui concerne les relations de l'islam avec les grandes religions présentes dans le monde musulman médiéval, en l'occurrence le judaïsme et le christianisme. Ici aussi le phénomène d'interaction réciproque est massivement en œuvre. Juifs, Chrétiens et Musulmans, aussi bien éduqués qu'illettrés, avaient comme langue commune l'arabe (et parfois le persan) et partageaient par conséquent un fonds culturel commun. En ce qui concerne les lettrés, lisant souvent les mêmes livres, parlant et écrivant une même langue, ils créèrent une forme de communauté intellectuelle unique où la norme fut, pendant des siècles, un échange constant des idées, des textes et des formes de discours. Cette caractéristique du monde musulman médiéval - qui a été à juste titre qualifiée de "pollinisation réciproque» ("crosspollination"; Goodman 1995; 1999. Montgomery 2007) ou d' " effet tourbillon" ("whirlpool effect"; Stroumsa 2008) implique qu'aucune étude consacrée à la théologie rationaliste islamique ne pourra désormais faire l'impasse sur l'interaction entre ces trois religions et que la perspective unidimensionnelle encore dominante dans la recherche moderne doit céder la place à une véritable approche multidimensionnelle.

Il est dorénavant quasi unanimement admis parmi les spécialistes que les méthodes dialectiques du kalām tirent leur origine 
des techniques rhétoriques des «dialogues dilemmatiques » qui caractérisaient les controverses christologiques de l'Alexandrie du $6^{\mathrm{e}}$ siècle ou encore plus de la Syrie du $7^{\mathrm{e}}$ siècle (Cook 1980. Zimmermann 1985. Brock 1986. Hoyland 1997. Reynolds 2004). Les théologiens rationalistes musulmans ont déployé de véritables mines d'idées, de méthodes et d'énergies pour l'examen critique et la réfutation des points de vue chrétiens - et dans une moindre mesure juifs - comme cela se manifeste à travers leurs nombreux traités polémiques. La grande majorité de leurs réfutations dirigées contre le christianisme semblent perdues à jamais mais quelques rares textes entiers nous sont parvenus du $9^{\mathrm{e}}$ siècle et nous permettent d'avoir une idée assez claire des arguments déployés (Thomas 2004). Quelques exemples représentatifs de ce genre littéraire parvenus jusqu'à nous et datant du $10^{\mathrm{e}}$ siècle sont le volumineux Kitāb Tathbìt dalà'il al-nubuwwa du mu'tazilite 'Abd al-Jabbār al-Hamadhānī (Reynolds 2004) et, du côté ash'arite, le Shifä' al-ghalīl d'al-Juwaynī ou encore le Radd al-jamīl liilāhiyyat 'İsa bi-ṣarị̄̂ al-Injīl attribué - probablement à juste titre - à al-Ghazālī (El-Kaisy Friemuth 2007. Thomas 2007).

Dans le camp opposé, en revanche, bon nombre d'écrits en arabe en défense du christianisme ont été préservés et parvenus jusqu'à nous. Il s'agit d'œuvres de théologiens représentant les trois principaux groupes chrétiens présents au Moyen-Orient pendant le premier siècle abbasside, par exemple le melkite Théodore Abū Qurra (m. ca. 830), le nestorien 'Ammār al-Bașrī (m. ca. 845) ou le jacobite Habīb b. Khidma Abū Rā'ița (m. ca. 855). Nous savons, grâce aux sources islamiques, que ces trois théologiens chrétiens étaient en dialogue constant avec leurs collègues rationalistes musulmans. D'après leurs arguments pour défendre les doctrines chrétiennes systématiquement visées par les Musulmans - celles concernant la Trinité, l'Incarnation, le baptême, l'eucharistie, la vénération de la croix ou encore la direction de la prière il semble évident que ces théologiens chrétiens étaient parfaitement au fait des techniques et du lexique du kalām (Troupeau 1995. Griffith 2002). En même temps, étant donné le caractère fondamental des désaccords entre certaines positions théologiques chrétiennes et musulmanes, par exemple l'incompatibilité entre la conception islamique de l'unicité divine (tawhīd) et la compréhension chrétienne des dogmes de la Trinité et de l'Incarnation, 
aucune adoption des doctrines islamiques par les théologiens chrétiens n'était envisageable (Troupeau 1962). Le seul cas de réception de certains aspects du kalām se rencontre parmi les auteurs chrétiens coptes. Il est vrai que le premier grand penseur copte écrivant en arabe, à savoir Sévère (Severus = Sawīrūs) Ibn al-Muqaffa ${ }^{\circ}$ (m. après 987) est un auteur assez tardif; mais ses écrits ouvrirent la voie aux théologiens coptes des siècles suivants pour produire un immense corpus d'écrits chrétiens en langue arabe qui dépasse de loin en volume l'ensemble des écrits de toutes les autres communautés arabes chrétiennes réunies (Graf 1947 : 294sqq. Sidarus 1993). Comme il a été démontré dans le cas de deux théologiens coptes du $13^{\mathrm{e}}$ siècle, Abū Shākir Ibn al-Rāhib et al-Mu'taman Ibn al-'Assāl, les penseurs coptes de l'époque ont été profondément influencés par le théologien ash'arite Fakhr al-Dīn al-Rāzī (Sidarus 1975. Wadi 1997. Schwarb à paraître).

Le judaïsme s'est montré beaucoup plus perméable aux notions doctrinales islamiques, y compris la doctrine de l'unicité divine. C'est surtout le mu 'tazilisme qui fut adopté à des degrés divers à partir du $9^{\mathrm{e}}$ siècle, aussi bien par les penseurs rabbanites que karaïtes, et finalement apparut au tournant du $11^{\mathrm{e}}$ siècle le célèbre mouvement du « mu'tazilisme juif ». Les savants juifs composèrent d'une part des œuvres originales selon la pensée mu'tazilite et copièrent d'autre part les ouvrages en arabe appartenant à celle-ci, souvent en caractères hébraïques. Les premiers exemples des ouvrages originaux des mu'tazilites juifs sont : le Kitāb al-Muḅtawī du karaïte Yūsuf al-Bașīr (m. ca. 1040) et son abrégé le Kitāb al-Tamyīz (Vajda 1985. Sklare 1995. von Abel 2005. Madelung \& Schmidtke 2006), le Kitāb al-Ni 'ma de l'aîné contemporain de ce dernier, Levi ben Yefet (Sklare 2007) ou encore le Kitāb al-Tawriya de l'élève d'al-Bașīr, Yeshu'a ben Yehudah. L'influence des $\mathrm{Mu}^{\text {'tazilites }}$ fraya son chemin jusqu'au cœur du centre religieux et intellectuel du judaïsme en Orient. En effet, nombreux chefs des anciennes académies rabbiniques (Yeshivot) de Sura et de Pumbedita (établies à partir du $10^{\mathrm{e}}$ siècle à Bagdad) adoptèrent la vision du monde mu'tazilite. L'un d'entre eux, Samuel ben Hofni Gaon (m. 1013), lecteur assidu d'Ibn Khallād, connaissait personnellement Abū 'Abdallāh al-Bașrī (Sklare 1996). En plus, comme ce fut le cas avec les penseurs chrétiens, doctrines et terminologies mu'tazilites fournirent la principale base aux discussions et polémiques entre 
savants juifs et musulmans (Sklare 1999). Par ailleurs, l'influence du shi'isme ismaélien sur certains théologiens rationalistes juifs du Moyen Âge a été démontrée par S. Pines et d'autres (Pines 1947; 1980. Blumenthal 1981. Kiener 1984). En revanche, les thèses et les écrits des Ash'arites reçurent un accueil beaucoup plus mitigé parmi les théologiens juifs et furent souvent critiqués par eux (Sinai 2005).

Le mu'tazilisme laissa également ses traces dans la pensée théologique samaritaine, par exemple chez l'auteur du $11^{\mathrm{e}}$ siècle Abū l-Ḥasan al-Ṣūrī. On ne sait pas encore clairement si les Samaritains - dont les principaux centres intellectuels aux $9^{\mathrm{e}}$ et $10^{\mathrm{e}}$ siècles se trouvaient à Naplouse et à Damas - ont étudié les écrits mu'tazilites musulmans de manière directe ou bien grâce aux adaptations juives de ceux-ci. La plupart des ouvrages théologiques samaritains en langue arabe attendent encore une analyse serrée, mais même un examen rapide des manuscrits existants tend à montrer que le cas d'Abū l-Ḥasan al-Ṣūī était loin d'être isolé (Wedel 2007).

On pourra citer beaucoup d'autres cas illustrant cette " pollinisation réciproque » très présente dans le monde musulman médiéval. Les deux exemples suivants suffiront pour démontrer, s'il en était encore besoin, que désormais une approche transversale et interdisciplinaire est indispensable pour saisir ce phénomène dans sa globalité. Le plus ancien traité existant du kalām systématique a été rédigé par Dāwūd b. Marwān al-Muqammaṣ, savant juif converti au christianisme et puis reconverti au judaïsme. Al-Muqammas fut le disciple du théologien jacobite Nonnus de Nisibe (m. ca. 870) et son ouvrage 'Ishrūn maqāla présente clairement aussi bien des caractéristiques de la théologie rationaliste islamique que les doctrines théologiques chrétiennes alors que la perspective générale du livre reste indubitablement juive (Stroumsa 1987; 2007). Le second exemple concerne le grand savant voyageur juif Mūsā b. Maymūn al-Qurțūbī, dit Maïmonide de Cordoue (m. 1024), bien connu de la littérature islamique et massivement reçu parmi les intellectuels musulmans et chrétiens comme cela est illustré par les innombrables vestiges de son Guide des perplexes dans les ouvrages islamiques et chrétiens (Schwarb 2007). 


\section{EXAMENS HISTORICO-CRITIQUES : NÉCESSITÉ DE TRANSVERSALITÉ DES ÉTUDES SUR LES MONOTHÉISMES}

\section{Le mu'tazilisme et le shi'isme rationaliste}

Dans le champ des études islamologiques, la recherche sur la théologie rationaliste islamique est une discipline relativement jeune pour la simple raison que la masse critique des sources primaires n'a été atteinte que relativement récemment. Les ouvrages mu'tazilites n'ont pas été fréquemment copiés et un nombre relativement peu élevé de manuscrits ont survécu au passage du temps. Jusqu'à la publication de textes significatifs dans les années 1960, peu d'écrits mu'tazilites authentiques étaient disponibles et les dif-

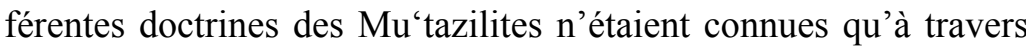
l'exposé de leurs adversaires. L'étude de la pensée mu'tazilite a été lente mais régulière tout le long du $20^{\mathrm{e}}$ siècle. Théoriquement banni du centre du monde sunnite depuis le $11^{\mathrm{e}}$ siècle, le système mu 'tazilite n'était pas considéré, par les spécialistes, comme faisant partie de l'histoire intellectuelle de l'islam. À cause de l'approche rationnelle des données théologiques par les Mu'tazilites, les historiens du $19^{\mathrm{e}}$ siècle les considéraient comme les « libres penseurs » de la culture islamique, profondément influencés par la philosophie grecque et constituant donc une sorte d'anomalie au sein de l'histoire intellectuelle islamique (par ex. Steiner 1865).

Cette évaluation, principalement fondée sur les écrits hérésiographiques des auteurs non-mu'tazilites, s'est évidemment avérée fausse au début $\mathrm{du} 20^{\mathrm{e}}$ siècle après la publication de plusieurs textes significatifs. En 1925, le savant suédois Henrik Samuel Nyberg édita le Kitāb al-Intișār du mu'tazilite bagdadien Abū 1-Husayn al-Khayyāt (m. ca. 913), réfutation du traité polémique du sceptique Ibn al-Rāwandī (m. 860 ou 912), la Fadīḥat al-Mu 'tazila, traité rédigé lui-même contre l'ouvrage pro-mu'tazilite d'al-Jāḥiz (m. 868), le Kitāb Fadìlat al-Mu'tazila (Nyberg 1925). Il est vrai qu'à cause de son caractère apologétique, le livre d'al-Khayyāt ne contient pas beaucoup d'informations sur les points de vue des Mu'tazilites, mais il était le tout premier écrit authentique issu de ces derniers et édité de manière critique. Beaucoup plus significative pour l'étude du mu'tazilisme fut l'édition, par Hellmut Ritter, de l'ouvrage hérésio-doxographique d'Abū 1-Hasan al-Ash'arī, 
les Maqālāt al-islāmiyyin, publiée en 1929-1930. Cet important ouvrage fournit de très représentatifs aperçus sur les positions mu'tazilites, étant donné que son auteur, comme on l'a dit auparavant, fut à l'origine mu'tazilite et était donc familier avec les écrits appartenant à cette École.

L'étape décisive suivante dans l'étude de la pensée mu'tazilite fut la découverte, lors d'une expédition d'un groupe de savants égyptiens au début des années 1950, d'un certain nombre de manuscrits au Yémen. Ces documents contenaient principalement les écrits des représentants de l'École des Bahshamiyya, y compris quatorze des vingt volumes originaux du Kitāb al-Mughnī fì abwāb altawhīd wa l-'adl, ouvrage encyclopédique du Cadi 'Abd al-Jabbār al-Hamadhānī lequel fut par conséquent édité en Égypte, de 1961 à 1965. De même, d'autres écrits des partisans de la Bahshamiyya trouvés dans la bibliothèque de la Grande Mosquée de Sanaa furent édités durant les années 1960. Parmi eux, il convient de mentionner le Ta'līq Sharḅ al-uṣull al-khamsa, une recension du Sharḅ alușül al-khamsa de 'Abd al-Jabbār fait par un de ses adeptes, l'imam shi'ite zaydite Mānakdīm (m. 1034) (Mānakdīm 1965), ainsi que le Kitāb al-Majmū' fi l-Muḅit bi-l-taklīf, une recension du Kitāb al-Mubīt bi-l-taklīf du même 'Abd al-Jabbār par un autre de ses disciples nommé Ibn Mattawayh (Ibn Mattawayh 1965; 1981; 1999).

Cependant, malgré ces riches moissons, de nombreuses lacunes persistaient encore. D'une part, fort peu de textes issus des auteurs plus anciens que 'Abd al-Jabbār étaient découverts. La même remarque s'appliquait aux écrits des rivaux de l'École des Bahshamiyya tels les Ikhshīdiyya ou encore les adeptes de l'École mu'tazilite de Bagdad. D'autre part, des parties significatives des écrits des adhérents de la Bahshamiyya restaient encore introuvables. Par exemple, les volumes 1 à 3, 10, 18 et 19 du Mughnī n'étaient pas encore découverts, ni d'autres ouvrages de 'Abd al-Jabbār, comme la version originale du Kitāb al-Muḅit ou son Sharḅ Kashfal-a 'räd. Par ailleurs, les découvertes des années 1950 avaient donné à croire que les Bahshamiyya constituaient la dernière tendance innovante et dynamique à l'intérieur du mu'tazilisme historique. Or, le caractère erroné de cette impression fut prouvé quelques décennies plus tard après la découverte et l'édition du Kitāb al-Mu 'tamad fì uṣul al-dīn et du Kitāb al-Fā'iq fì uṣūl al-dīn de Rukn al-Dīn Muhammad b. Maḥmūd al-Malāḥimī (m. 1141) par Wilferd Madelung et Martin 
McDermott (Ibn al-Malāḥimī 1991; 2007). Ibn al-Malāḥimī fut adepte des enseignements d'Abū 1-Husayn al-Bașrīi. De ce qui ressort de ses écrits, il semble évident que ce dernier avait développé des points de vue significativement différents de ceux de son maître 'Abd al-Jabbār et avait formulé de nouvelles positions rationalistes sur un certain nombre de doctrines centrales. Et pourtant on n'a trouvé nulle trace des écrits d'Abū l-Husayn au Yémen. Ceux de ses adversaires contemporains, illustrant les véhémentes discussions entre les partisans des Bahshamiyya et Abū l-Husayn, n'ont pas été découverts non plus. L'existence et l'intensité de ces polémiques ne sont connues pour le moment qu'à travers les témoignages indirects des sources postérieures. Par ailleurs, l'étude de ce que l'on pourrait appeler « le mu'tazilisme shi' ite imamite » est maintenant facilitée grâce à la publication, entre autres, d'un très grand nombre d'écrits des « fondateurs » de ce mouvement à savoir al-Mufīd et son disciple al-Sharīf al-Murtaḍā, principalement par les savants shi'ites iraniens (voir bibliographie).

L'étude du mu'tazilisme juif commença il y a plus d'un siècle avec les travaux de Salomon Munk (1859) et ceux de Martin Schreiner (1895). Ces deux savants n'étaient pourtant pas au courant de la découverte de sources primaires au sein des documents provenant de différentes Genizot trouvés et restaurés, dans la seconde moitié du $19^{\mathrm{e}}$ siècle au Caire, par un certain nombre de savants et de collectionneurs de manuscrits. Treize parmi les manuscrits mu'tazilites de la collection Abraham Firkovitch de Saint-Pétersbourg (provenant de la Genizah de la synagogue karaïte du Caire) furent minutieusement décrits par Borisov dans un article publié en 1935. Entre 1939 et 1943, Leon Nemoy édita le Kitāb al-Anwār wa l-marāqib du penseur karaïte Ya'qūb al-Qirqisānī (vivant au début $\mathrm{du} 10^{\mathrm{e}}$ siècle à Bagdad). Une autre étape marquante des études du mu'tazilisme juif furent la parution de Repercussions of the Kalam in Jewish Philosophy de Harry A. Wolfson (1979) et celle des œuvres de Yūsuf al-Bașīr, notamment son Kitāb al-Muḅtawī (sur la base d'un manuscrit de la collection Kaufmann de Budapest), par Georges Vajda (1985). Haggai Ben-Shammai étudia les éléments mu'tazilites présents dans les œuvres des premiers auteurs karaïtes du $10^{\mathrm{e}}$ siècle, en l'occurrence Ya 'qūb al-Qirqisān̄i, déjà mentionné, et Yefet ben 'Eli (Ben-Shammai 1978). À partir des descriptions des manuscrits mu'tazilites de la collection Firkovitch par Borisov 
ainsi que grâce aux fragments conservés à la British Library, BenShammai put tirer de nouvelles et convaincantes conclusions sur l'identité des matériaux mu'tazilites préservés par les Karaïtes, en montrant en particulier que ceux-ci avaient conservé la version originale du Kitāb al-Muḅit de 'Abd al-Jabbār (Ben-Shammai 1974). Sarah Stroumsa publia les 'Ishrūn maqāla de Dāwūd b. Marwān al-Muqammaș (Stroumsa 1989; 2007) et David Sklare a pu reconstituer certains écrits mu'tazilites de Samuel ben Hofni Gaon (Sklare 1996); ce dernier étudia en outre l'influence de la pensée mu'tazilite sur les ouvrages juridiques de Yūsuf al-Bașīr (Sklare 1995).

En 2003, le « Mu'tazilite Manuscripts Project Group » fut fondé par Sabine Schmidtke et David Sklare dans le but d'assembler et d'identifier le plus de manuscrits mu'tazilites possibles à partir des fonds juifs et shi'ites. Parmi les plus remarquables découvertes des membres de ce groupe on peut mentionner trois gros fragments du Kitāb Tașaffuḅ al-adilla d'Abū 1-Ḥusayn al-Bașrī que l'on croyait définitivement perdus (Madelung \& Schmidtke 2006a), ainsi que des fragments de deux réfutations des doctrines d'Abū 1-Husayn par son contemporain, le théologien karaïte Yūsuf al-Bașīr (Madelung \& Schmidtke 2006; 2007). Certaines parties du Mughnī de 'Abd al-Jabbār, provenant des volumes absents du fonds des manuscrits yéménites, ont été retrouvées et éditées (Schmidtke 2007. Hamdan \& Schmidtke, 2008. Schwarb, 2008). Un commentaire anonyme du Kitāb al-Tadhkira d'Ibn Mattawayh, préservé dans un manuscrit apparemment unique de la Bibliothèque Așghar Mahdavī à Téhéran, a été rendu disponible aux chercheurs dans une édition en fac-similé (Schmidtke 2006). Enfin, de nombreux écrits mu'tazilites présumés perdus ont été récemment retrouvés au Yémen et en Inde. Parmi eux, la Tubfat al-mutakallimīn fì radd 'alā l-falāsifa, ouvrage antipéripatéticien d'Ibn al-Malāḥimī, est maintenant éditée de manière critique par Hasan Anșārī et Wilferd Madelung (Ibn al-Malāḥimī 2008).

Malgré tout ce qui a été réalisé ces dernières années, un grand nombre de textes mu'tazilites demeure encore inexploré. Parmi les nombreux documents provenant de différentes collections des Genizot, le matériau originaire de la Genizah Ben Ezra du Caire, se trouvant principalement dans la collection Taylor-Schechter de la bibliothèque de l'Université de Cambridge (et d'autres bibliothèques européennes et américaines), est encore très insuffisam- 
ment identifié et incomplètement catalogué (Baker \& Polliack 2001. Shivtiel \& Niessen 2006). On peut espérer que l'étude systématique de tous ces fragments mu'tazilites facilitera la reconstitution d'un nombre aussi grand que possible d'écrits musulmans et juifs appartenant à cette École (Adang et al.2007). Ces documents de Genizah vont certainement compléter significativement ceux du même genre de la collection Firkovitch de Saint-Pétersbourg lesquels n'ont été explorés que très partiellement (Schmidtke 2007). Par ailleurs, c'est seulement depuis quelques années que les riches fonds des petites bibliothèques publiques ainsi que les fonds privés du Yémen ont été ouverts à la communauté scientifique surtout grâce aux efforts de l'Imam Zayd bin Ali Cultural Foundation (IZBACF : www. izbacf.org). Certains éléments de ce matériau ont été exploités pour diverses publications par les membres du « Mu'tazilite Manuscripts Project Group » mais la très grande majorité d'entre eux n'ont pas encore été étudiés. Cette dernière remarque est également applicable à l'étude de la pensée mu'tazilite tel qu'elle s'est développée parmi les Shi'ites Zaydites depuis le $12^{\mathrm{e}}$ siècle.

L'étude de la littérature samaritaine en langue arabe en général et du mu'tazilisme samaritain en particulier n'est encore qu'à ses débuts. Le seul texte pertinent partiellement édité et étudié est le Kitāb al-Ṭubākh (ou Țabbākh) de l'auteur du 11 $1^{\mathrm{e}}$ siècle Abū 1-Hasan al-Ṣūrī, clairement influencé par les doctrines mu'tazilites (Wedel 1987; 2007). Cet état de fait est d'autant plus déplorable que les conditions idéales pour un examen systématique de la pensée théologique des Samaritains en langue arabe sont maintenant réunies; en effet, la bibliothèque de l'Institut des Études Arabes et Sémitiques de Freie Universität de Berlin dispose d'un microfilm qui contient théoriquement la totalité du corpus littéraire samaritain en langue arabe, à l'exclusion du matériau se trouvant dans la collection Firkovitch (voir www.geschkult.fu-berlin.de/e/semiarab/).

\section{L'Ash'arisme}

Contrairement aux études mu 'tazilites qui débutèrent assez tardivement, la recherche sur l'ash'arisme commença dès le $19^{\mathrm{e}}$ siècle car beaucoup plus de manuscrits appartenant à cette École se trouvaient dans les bibliothèques européennes. En 1876, Wilhelm Spitta publia la première étude monographique sur le fondateur éponyme 
de l'École, et en 1889 Martin Schreiner écrivit la première histoire synthétique des Ash'arites. Le Kitāb al-Irshād d'al-Juwayn̄̄ fut édité de manière critique en 1938 par Jean-Dominique Luciani avec une traduction française. Les étapes importantes suivantes au $20^{\mathrm{e}}$ siècle furent les travaux de Richard J. McCarthy. En 1953, celui-ci publia une monographie contenant l'édition critique et la traduction anglaise de la plupart des écrits existants d'al-Ash'arī et en 1957 l'édition critique du Kitāb al-Tamhīd d'al-Bāqillānī. Une pénétrante étude historique du développement de l'École jusqu'à l'époque d'al-Juwaynī fut effectuée par Michel Allard (1965) qui publia également l'édition critique de deux textes importants d'alJuwaynī, le Shifā' al-ghalīl et les Luma ' fì qawā 'id ahl al-sunna wal-jamā'a (Allard 1968). Au cours de ces dernières décennies, des avancées notables ont été réalisées dans les études ash'arites grâce aux nombreuses publications de Richard M. Frank (par ex. 1994; 2007) et de Daniel Gimaret $(1985 ; 1987$; 1990). Parallèlement aux chercheurs occidentaux, un certain nombre de savants musulmans aussi ont significativement contribué à l'étude des textes ash 'arites (par ex. al-Bukhtī 2005).

En dépit de ces progrès, il reste encore beaucoup à faire dans l'examen critique de la pensée ash'arite, en particulier pour ce qui est sa phase ancienne, soit avant al-Ghazālī. Des deux plus éminents théologiens de cette phase, à savoir al-Bāqillānī et al-Juwaynī, nous avons finalement un nombre très limité d'écrits et dans les deux cas les ouvrages majeurs de chacun d'entre eux - soit la Hidāyat almustarshidīn d'al-Bāqillān̄̄ et le Kitāb al-Shāmil d'al-Juwayn̄̄ - ne nous sont apparemment parvenus que partiellement. En plus, beaucoup d'autres penseurs de cette même période dont les ouvrages contiennent de précieuses informations sur les doctrines de diverses tendances de l'École, n'ont pas encore été édités et demeurent par conséquent peu étudiés. Dans quelle mesure ces textes inédits pourront bouleverser nos acquis actuels? Nous pourrons en avoir une idée par le Mujarrad maqālāt al-Ash 'arī. Ce livre fut édité par Daniel Gimaret en 1987 à partir du seul manuscrit existant préservé à Médine (Gimaret 1987). C'est sur la base de ce texte que le savant français put écrire son ouvrage aussi fondamental qu'original et encore non dépassé sur la pensée doctrinale du fondateur de l'École ash'arite (Gimaret 1990). Le Kitāb al-Irshād d'al-Juwayn̄̄, épitomé de son Kitāb al-Shāmil, donna lieu à un certain nombre 
de commentaires de la part de ses élèves directs et partisans postérieurs comme cela s'avère du commentaire partiel d'Abū 1-Qāsim Salmān b. Nāṣir al-Nīsābūrī (m. 1118), la Ghunya fì l-kalām (MS III Ahmet 1916). Par ailleurs, le même Kitāb al-Shāmil, ouvrage partiellement retrouvé (éds. Klopfer 1959. Nashshār et al. 1969. Frank 1981. 'Umar 1999) a été fréquemment cité et souvent paraphrasé par les auteurs des mêmes commentaires. Nous avons également le manuscrit d'un ouvrage anonyme contenant un abrégé du livre d'al-Juwaynī et intitulé al-Kāmil fi khtișār al-Shāmil (MS III Ahmet 1322). On peut retrouver les citations du Kitāb al-Shāmil dans les summae théologiques d'autres élèves d'al-Juwaynī, par exemple Abū l-Ḥasan 'Alī al-Kiyā al-Harrāsī (m. 1110), préservé dans un manuscrit du Caire (Dār al-kutub, 'ilm al-kalām 290). Une recherche fouillée des catalogues de manuscrits arabes mettra sans aucun doute au jour beaucoup d'autres matériaux insoupçonnés.

Par ailleurs, la quasi totalité des écrits en arabe de la première génération des mutakallimūn chrétiens sont maintenant édités et en partie traduits dans une langue occidentale (Bacha 1904. Graf 1910; 1951. Hayek 1977. Lamoreaux 2005), et les experts du domaine, tels Sydney H. Griffith et David Thomas (voir la bibliographie), les ont étudiés minutieusement. De même, la totalité des rares écrits anti-chrétiens de théologiens rationalistes musulmans ont été édités de manière critique (di Matteo 1921-1922. Finkel 1926. Thomas 2002). Par contre, comme on l'a déjà souligné, le travail est à peine commencé sur le vaste corpus des écrits de savants chrétiens coptes, encore très insuffisamment édités et étudiés. Ce travail est d'autant plus nécessaire que ces écrits ont joué un rôle non négligeable dans le processus de "pollinisation réciproque » de l'histoire intellectuelle du monde musulman médiéval.

\section{NOUVELLES PERSPECTIVES DE RECHERCHE}

L'étape suivante de la recherche dans le domaine qui nous occupe se doit de se concentrer sur le rationalisme théologique dans le monde musulman médiéval à travers et au-delà des frontières qui séparent les trois grands monothéismes, le judaïsme, le christianisme et l'islam. À quelques rares périodes près, l'échange continuel et la circulation des idées, des textes et des formes de dis- 
cours furent la norme parmi les intellectuels de ces trois religions. Malgré cette réalité dorénavant largement acceptée par la communauté scientifique, la majorité des chercheurs optent encore pour une approche unidimensionnelle des auteurs et écrits appartenant à l'une des communautés religieuses à l'exclusion des autres, en restant dans les frontières toujours rigides des trois domaines scientifiques concernés, à savoir les études islamiques, les études juives et les études chrétiennes orientales. Cet état de fait est appelé à céder progressivement sa place à une approche multidimensionnelle, transversale et interdisciplinaire justifiée et exigée par la réalité historique des périodes et des régions étudiées. De plus, dans une telle initiative, le chercheur est invité à avoir des contacts constants avec les principaux acteurs scientifiques de ces trois domaines lesquels demeurent séparés non seulement par les frontières disciplinaires mais aussi par les limitations d'ordre politique. Autrement dit, une coopération plus soutenue est plus que souhaitable entre les chercheurs occidentaux, y compris les Israéliens, et les savants issus du monde musulman pour faire naître une nouvelle dynamique de recherche. Plus qu'un vœu pieux, ce souhait est beaucoup moins utopique qu'il ne paraît au premier abord car de rares mais solides coopérations de ce genre ont déjà eu lieu et porté leurs fruits. Une des caractéristiques remarquables de l'histoire intellectuelle a toujours été le dépassement des obstacles nationaux, religieux et culturels et l'échange intellectuel, voire la symbiose, a été beaucoup plus souvent la norme que l'exception pendant le Moyen Âge et les temps pré-modernes. Aujourd'hui, l'initiative est particulièrement indispensable et salutaire dans une des zones les plus conflictuelles du monde actuel, à savoir le Moyen-Orient ${ }^{1}$.

Mohammad Ali Amir-Moezzi,

École Pratique des Hautes Études, Sorbonne,

45 rue des Ecoles, 75005 Paris.

Sabine Schmidtke,

Institut für Islamwissenschaft, Altensteinstr.

40, D-14195, Berlin.

1. Une version plus brève de cette publication a été préparée, en anglais, dans le cadre du projet «Rediscovering Rationalism in the Medieval World of Islam » au sein de l'European Research Council (FP 7), 2008. 


\section{BIBLIOGRAPHIE}

'Abd al-Jabbār al-Hamadhānī (1961-1965), Kitāb al-Mughnī fì abwāb altawhìd wa-l- 'adl, éd. Hilmī et al., Le Caire.

Von ABel, Wolfgang (2005), Yūsuf al-Bașī, Das Buch der Unterscheidung. Judäo-arabisch-Deutsch. Übersetzt und eingeleitet, Freiburg.

Adang, Camilla, Schmidtke, Sabine, Sklare, David. (eds.) (2007), A Common Rationality. Mu'tazilism in Islam and Judaism, Würzburg.

Allard, Michel (1965), Le problème des attributs divins dans la doctrine d'al-Ǎ̌ 'arī et de ses premiers grands disciples, Beyrouth.

Allard, Michel (1968), Textes apologétiques de Ğuwaynī, Beyrouth.

Amir-Moezzi, Mohammad Ali (1992), Le Guide divin dans le shî isme originel, Paris-Lagrasse (nouvelle édition 2007).

Amir-Moezzi Mohammad Ali (1993), «Réflexions sur une évolution du shi'isme duodécimain : tradition et idéologisation ", Patlagean, Evelyne \& Le Boulluec, Alain (éds.), Les retours aux Écritures. Fondamentalismes présents et passés, Louvain-Paris, p. 63-82.

Amir-Moezzi, Mohammad Ali \& JamBet, Christian (2004), Qu'est-ce que le shi'isme?, Paris.

AnsĀri, Hasan (2001), « Ketāb-ī tāzeh yāb dar naqd-e falsafa. Peydā shodan-e ketāb-e Tuḅfat al-mutakallimīn-e Malāhimīì », Nashr-i Dānish 18/3, p. 31-32.

BACHA, Constantin (1904), Les auvres arabes de Théodore Aboucara, Beyrouth.

BADEEN, Edward (2008), Sunnitische Theologie in osmanischer Zeit, Würzburg.

Baker, Colin \& Polliack, Meira (2001), Arabic and Judaeo-Arabic Manuscripts in the Cambridge Genizah Collections. Arabic Old Series (T-S Ar. 1a-54), Cambridge.

Ben-Shammai, Haggai (1974), «A note on some Karaite copies of $\mathrm{Mu}$ 'tazilite writings », Bulletin of the School of Oriental and African Studies 37, p. 295-304.

Ben-Shammai, Haggai (1978), The Doctrines of Religious Thought of Abu Yūsuf Ya' 'qūb al-Qirqisānī and Yefet ben 'Eli, Thèse de Doctorat, Université Hébraïque de Jérusalem. 
Blumenthal, David R. (1981), « An example of Ismaili influence in postMaimonidean Yemen », Morag, Shelomo et al. (eds.), Studies in Judaism and Islam presented to Shlomo Dov Goitein, Jérusalem, p. 155-74.

Borisov, A.J. (1935), « Mu'tazilitskie rukopisi Gosudarstvennoj Publicnoj Biblioteki v Leningrade », Bibliografija Vostoka 8-9, p. 69-95.

Brock, Sebastian P. (1986), « Two Sets of Monothelete Questions to the Maximianists », Orientalia Lovanensia Periodica 17, p. 119-40.

BukHTī, 'Abd al-Jabbār (2005), 'Uthmān al-Salājī wa-madhhabiyyatuhu l-ash'ariyya. Dirāsa li-jānib min al-fikr al-kalāmī bi-l-Maghrib min khilāl « al-Burhāniyya » wa shurūḅihā, Rabat.

CooK, Michael (1980), « The Origins of Kalām », Bulletin of the School of Oriental and African Studies 43, p. 32-43.

Coок, Michael (1981), Early Muslim dogma. A source-critical study, Londres.

El-Kaisy Friemuth, Maha (2007), «Al-Radd al-jamīl: al-Ghazālī’s or Pseudo-Ghazālī's? », Thomas, D. (ed.), The Bible in Arab Christianity, Leiden, p. 275-94.

EndRESS, Gergard (1997), « The Circle of al-Kindī. Early Arabic Translations from the Greek and the Rise of Islamic Philosophy », ENDRESS, Gerhard \& KRUK, Remke (eds.), The Ancient Tradition in Christian and Islamic Hellenism. Studies on the Transmission of Greek Philosophy and Sciences Dedicated to H.J. Drossaart Lufoli on his Ninetieth Birthday, Leiden, p. 43-76.

van Ess, Josef(1975), " The Begennings of Islamic Theology », Murdoch, John Emery \& Dudley Sylla, Edith (eds.), The Cultural Context of Medieval Learning, Hollanda, p. 87-115.

van Ess, Josef (1978), Anfänge muslimischer Theologie, Beyrouth.

van Ess, Josef (1991-97), Theologie und Gesellschaft im 2. und 3. Jahrhundert Hidschra, Berlin et New York.

Finkel, Joshua (éd.) (1926), Thalāth rasā'il li-Abī 'Uthmān...al-Jāḅiz, Le Caire (contient al-Radd 'alā l-nașārā).

FrANK, Richard M. (1994), Al-Ghazālī and the Ash 'arite school, Durham.

FrANK, Richard M. (2007), Early Islamic Theology : the Mu'tazilites and al-Ash 'arī. Texts and Studies on the Development and History of Kalām, vol. II, Gutas, Dimitri (ed.), Ashgate. 
Frank, Richard M. (2008), Classical Islamic Theology: the Ash'arites. Texts and Studies on the Development and History of Kalām, vol. III, Gutas, Dimitri (ed.), Ashgate.

GiMARET, Daniel (1985), « Un document majeur pour l'histoire du kalām : le Muğarrad Maqālāt al-Ǎs 'arī d'Ibn Fūrak », Arabica 32, p. 185-218.

Gimaret, Daniel (éd.) (1987), Abū Bakr b. Fūrak (m. 406/1015) : Muğarrad Maqālāt al-Aš 'arì (Exposé de la doctrine d'al-Aš́ 'arī), Beyrouth.

Gimaret, Daniel (1990), La doctrine d'al-Ash 'arī, Paris.

Goodman, Lenn Evan (1995), «Crosspollinations - philosophically fruitful exchanges between Jewish and Islamic thought », Medieval Encounters 1, p. 323-57.

Goodman, Lenn Evan (1999), Jewish and Islamic Philosophy: Crosspollination in the Classical Age, Edimbourg.

Graf, Georg (1910), Die arabischen Schriften des Theodor Abū Qurra, Paderborn.

GRAF, Georg (1947), Geschichte der christlischen arabischen Literatur. Zweiter Band: Die Schriftsteller bis zur Mitte des 15. Jahrhunderts, Vatican.

Graf, Georg (1951), Die Schriften des Jacobiten Ibn Hidma Abū Rā'ița, Louvain.

Griffith, Sydney H. (2002), the Beginnings of Christian Theology in Arabic. Muslim-Christian Encounters in the Early Islamic Period, Ashgate.

Griffith, Sydney H. (2008), The Church in the Shadow of the Mosque : Christians and Muslims in the World of Islam, Princeton.

von Grunebaum, Gustav E. (ed.) (1970), Logic in Classical Islamic Culture, Wiesbaden.

Hamdan, Omar \& Schmidtke, Sabine (2008), « Qāḍ̄ 'Abd al-Jabbār alHamadhānī (d. 415/1025) on the Promise and Threat. An Edition of a Fragment of his Kitāb al-Mughnī fí abwāb al-tawhīd wa l- 'adl Preserved in the Firkovitch-Collection, St. Petersburg (II Firk. Arab. 105, ff. 1492) », Mélanges de l'Institut Dominicain d'Études Orientales 27, p. 37117.

HAYEK, Michel (1977), 'Ammār al-Bașìr, théologie et controverses, Beyrouth. 
HildeBrandt, Thomas (2007), Neo-Mu'tazilismus? Intention und Kontext im modernen arabischen Umgang mit dem rationalistischen Erbe des Islam, Leiden.

Hoyland, Robert G. (1997), Seeing Islam as Others Saw It. A Survey and Evaluation of Christian, Jewish and Zoroastrian Writings on Early Islam, New Jersey.

Ibn al-Malāḥimī, Rukn al-Dīn (1991), Kitāb al-Mu 'tamad fì uṣūl al-dīn, éd. McDermott, Martin \& Madelung, Wilferd, Londres.

Ibn al-Malāhimīē, Rukn al-Dīn (2007), Kitāb al-Fā'iq fì uṣūl al-dīn, éd. Madelung, Wilferd \& McDermott, Martin, Téhéran.

Ibn al-Malāhimīè, Rukn al-Dīn (2008), Kitāb Tubfat al-mutakallimīn $f i$ l-radd 'alā l-falāsifa, éd., AnsĀRī, Hasan. \& MAdelung, Wilferd, Téhéran.

Ibn Mattawayh (1965; 1981; 1999), Kitāb al-Majmū 'fì l-mubịt bi-l-taklīf, vol. 1, éd. Houben, Beyrouth; vol. 2, éd. Houben \& Gimaret, Beyrouth; vol. 3, éd. Peters, Beyrouth.

Juwayn̄̄, Imām al-Haramayn (1959?), al-Shāmil fì uṣūl al-dīn, éd. KLOPFER, Le Caire.

Juwaynī, Imām al-Ḥaramayn (1969), al-Shāmil fì uṣūl al-dīn, éd. ALNASHSHĀr-'Awn-MukHTĀR, Alexandrie.

Juwaynī, Imām al-Haramayn (1981), al-Shāmil fì uṣūl al-dīn, éd. Frank, Richard, Téhéran, 1360 solaire.

Juwaynī, Imām al-Ḥaramayn (1999), al-Shāmil fì uṣūl al-dīn, éd. 'UMAR, Beyrouth.

KeAting, Sandra T. (2005), « Refuting the charge of taḅrīf: Abū Rā'ița (d. ca. 835) and his 'First risāla on the Holy Trinity », GüNTHER, Sebastian (ed.), Ideas, Images and Methods of Portrayal : Insights into Classical Arabic Literature and Islam, Leiden, p. 41-57.

KIENER, Ronald C. (1984), « Jewish Ismā‘īlism in twelfth century Yemen : R. Nathanel ben al-Fayyūmī̄», Jewish Quarterly Review, 74/3, p. 24966.

Lamoreaux, John C. (2005), Theodore Abū Qurrah, Provo (Utah).

LuCiani, Jean-Dominique (éd. et trad. fr.) (1938), al-Irshād li Imām alHaramayn, Paris. 
Madelung, Wilferd (1970), « Imâmism and Mu'tazilite Theology », FAHD, Toufic (éd.), Le Shî 'isme imâmite. Actes du colloque de Strasbourg, 69 mai 1968, Paris, p. 13-29 (repris dans Madelung, W., Religious Schools and Sects in Medieval Islam, Londres, 1985, article 7).

Madelung, Wilferd (2006), «Abū 1-Husayn al-Bașrī's Proof for the Existence of God », Montgomery, J.E. (ed.), Arabic Theology, Arabic Philosophy. From the Many to the One: Essays in Celebration of Richard M. Frank, Leuven, p. 273-80.

Madelung, Wilferd \& Schmidtke, Sabine (2006), Rational Theology in Interfaith Communication. Abu l-Husayn al-Bașrī's Mu 'tazilī Theology among the Karaites in the Fạtimid Age, Leiden.

Madelung, Wilferd \& Schmidtke, Sabine (eds.) (2006a), Abu l-Husayn al-Baṣrī, Taṣaffụ̣ al-adilla, Wiesbaden.

Madelung, Wilferd \& Schmidtke, Sabine (2007), « Yūsuf al-Bașīr's First Refutation (Naqd) of Abu 1-Husayn al-Bașrī's Theology », ADANG, Camilla et al. (eds.), A Common Rationality (voir plus haut), p. 23096.

McCARthy, Richard J. (1953), The Theology of al-Ash 'arī, Beyrouth.

McCARThy, Richard J. (ed.) (1957), Kitāb al-Tamhìd (by) Abū Bakr Muḅammad ibn al-Ṭayyib al-Bāqillānī, Beyrouth.

Mc Dermott, Martin J. (1978), The Theology of Al-Shaikh al-Mufid (d. 413/1022), Beyrouth.

Mānakdīm, Abū 1-Husayn Aḥmad b. Abī Hāshim (1965), (Ta 'līq) Sharḅ al-Ușūl al-khamsa, éd. 'UthmĀN, (attribué à 'Abd al-Jabbār sur la page de titre!), Le Caire 1384.

MAS'ŪDī, 'Abd al-'Az̄̄z Qā'id (2008), Ishkāliyyat al-fikr al-zaydī fì l-Yaman al-mu'āṣir. Qirā'a fì l-qirā'āt al-sab' li-turāth Mu'tazilat al-'Irāq, Le Caire.

di Matteo, I. (1921-22), « Confutazione contro i Cristiani dello zaydita al-Qāsim b. Ibrāhīm », Rivista degli Studi Orientali 9, p. 301-64.

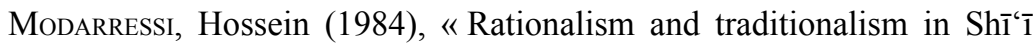
jurisprudence : a preliminary survey », Studia Islamica 59, p. 141-58.

Modarressi, Hossein (1993), Crisis and Consolidation in the Formative Period of Shī'ite Islam : Abū Ja 'far Ibn Qiba al-Rāzì and his Contribution to Imāmite Shī ite Thought, Princeton. 
Monnot, Guy (1974), Penseurs musulmans et religions iraniennes. 'Abd al-Jabbār et ses devanciers, Paris.

Monnot, Guy (1986), Islam et religions, Paris.

Montgomery, James (2007), « Islamic Crosspollinations », AkAsoy, Anna, Pormann, Peter \& Montgomery, James (eds.), Islamic Crosspollinations. Interactions in the Medieval Middle East, Oxford, p. 148-93.

Mufĩd, al-Shaykh Muhammad b. Muhammad (1993), Silsilat alMu'allafāt, 16 vols. (dont un d'introduction), Beyrouth 1414.

Munk, Salomon (1859), Mélanges de philosophie juive et arabe, Paris.

Nagel, Tilman (1988), Die Festung des Glaubens. Triumph und Scheitern des islamischen Rationalismus im 11. Jahrhunderts, Munich.

Nemoy, Leon (ed.) (1939-43), Kitāb al-Anwār wa l-Marāqib. Code of Karaite Law by Ya 'qūb al-Qirqisānī. Edited from Manuscripts in the State Library at Leningrad and the British Museum at London, New York.

Nyberg, Henrik Samuel (ed.) (1925), Le livre du triomphe et de la réfutation d'ibn er-Rawendi l'hérétique par Abou l-Hosein Abderrahim ibn Mohammed ibn Osman el-Khayyat, Le Caire.

L'Orient chrétien dans l'empire musulman. Hommage au Professeur Gérard Troupeau, sous la direction de URvoY, Marie-Thérèse, Paris, 2005.

Perler, Dominik \& Rudolph, Ulrich (2000), Occasionalismus. Theorien der Kausalität im arabisch-islamischen und im europäischen Denken, Göttingen.

PINES, Shlomo (1947), "Nathanaël ben al-Fayyûmî et la théologie Ismaëlienne », Revue de l'Histoire Juive en Égypte 1, p. 5-22.

PInEs, Shlomo (1980), « Shī'ite Terms and Conceptions in Judah Halevi's Kuzari », Jerusalem Studies in Arabic and Islam 2, p. 165-251.

Reynolds, Gabriel Said (2004), A Muslim Theologian in the Sectarian Milieu. 'Abd al-Jabbār and the Critique of Christian Origins, Leiden.

RitTER, Hellmut (éd.) (1929-30), Die dogmatischen Lehren der Anhänger des Islam von Abu l-Hasan 'Alī ibn Ismā 'ìl al-Aš 'arì, Istambul.

Rudolph, Ulrich (1997), Al-Māturīd̄̄ und die sunnitische Theologie in Samarkand, Leiden. 
Schmidtke, Sabine (2006), An Anonymus Commentary on Kitāb alTadhkira by Ibn Mattawayh. Facsimile Edition of Mahdavi Codex 514 (6th/12th Century), Introduction and Indices, Téhéran.

SchmidtKe, Sabine (2007), «Mu'tazilī Manuscripts in the Abraham Firkovitch Collection, St. Petersburg. A Descriptive Catalogue », Adang, Camilla et al. (eds.), A Common Rationality (voir plus haut), p. 377-462.

Schmidtke, Sabine (2008), «MS Mahdawi 514. An Anonymous Commentary on Ibn Mattawayh's Kitāb al-Tadhkira », AKAsoy, Anna \& Raven, Wim (eds.), Islamic Thought in the Middle Ages. Studies in Text, Transmission and Translation in Honour of Hans Daiber, Leiden, p. 139-162.

SchmidtKe voir sub Hamdan et Madelung.

Schreiner, Martin (1889), «Zur Geschichte des Aš‘aritenthums », Actes $d u 8^{e}$ Congrès International des Orientalistes, Stockholm, p. 79-117.

SCHREINER, Martin (1895), "Der Kalâm in der jüdischen Literatur », Bericht über die Lehranstalt für die Wissenschaft des Judenthums in Berlin 13, p. 1-67.

Schwarb, Gregor (2007); « Die Rezeption Maimonides' in der christlicharabischen Literatur », Judaica. Beiträge zum Verstehen des Judentums 61, p. 1-46.

SchwARB, Gregor (2008), «Découverte d'un nouveau fragment du Kitāb al-mughnī fì abwāb al-tawḅ̄d w-l- 'adl du Qāḍ̄ 'Abd al-Jabbār al-Hamadānī dans une collection karaïte de la British Library », Mélanges de l'Institut Dominicain d'Études Orientales 27, p. 119-29.

SchwARB, Gregor (à paraître), « The Reception of Fakhr al-Dīn al-Rāzī in the Christian Arabic Literature of the Thirteenth Century : Between Plagiarism and Polemics », Jerusalem Studies in Arabic and Islam 35.

Sharīf Murtaḍā, 'Alī b. al-Ḥusayn 'Alam al-Hudā (ca. 1984-85), Rasā'il, 3 vols. sous la direction de RAJĀ' $\overline{1}$, Beyrouth, s.d. (vers 1405/1984-85).

Sharīf Murtaḍā, 'Alī b. al-Ḥusayn 'Alam al-Hudā (1990), Al-Dhakhīra fì 'ilm al-kalām, éd. AL-HusaYNī, Aḥmad, Qumm, 1411.

Shivtiel, Avi \& Niessen, Friedrich (2006), Arabic and Judaeo-Arabic Manuscripts in the Cambridge Genizah Collections : Taylor-Schechter New Series, Cambridge.

SidArus, Adel Y. (1975), Ibn ar-Rāhibs Leben und Werk. Ein koptischarabischer Enzyklopädist des 7./13. Jahrhunderts, Freiburg. 
SidARus, Adel Y. (1993), « Essai sur l'âge d'or de la littérature copte arabe $\left(\mathrm{XI}^{\mathrm{e}}-\mathrm{XIV}^{\mathrm{e}}\right.$ siècles) », Acts of the Fifth International Congress of Coptic Studies. Washington, 12-15 August 1992, vol. 2, Johnson, David W. (ed.), Rome, p. 443-62.

SINAI, Nicolai (2005), Menschliche oder göttliche Weisheit? Zum Gegensatz von philosophischem und religiösem Lebensideal bei al-Ghazali und Yehuda ha-Levi, Würzburg.

Sklare, David (1995), "Yūsuf al-Bașīr : Theological Aspects of his Halakhic Works ", Frank, D. (ed.), The Jews of Medieval Islam. Community, Society and Identity, Leiden, p. 249-70.

Sklare, David (1996), Samuel ben Hofni Gaon and his Cultural World. Texts and Studies, Leiden.

Sklare, David (1999), «Responses to Islamic Polemics by Jewish Mutakallimūn in the Tenth Century », LAZARUS YAFEH - COHEN - SoMeKH - GRIFFITH (eds.), The Majlis. Interreligious Encounters in Medieval Islam, Wiesbaden, p. 137-61.

SKLARE, David (2007), " Levi ben Yefet and his Kitāb al-Ni 'ma », AdANG, Camilla et al. (eds.), A Common Rationality (voir plus haut), p. 157216.

SpITTA, Wilhelm (1876), Zur Geschichte des Abū l-Hasan al-Ash'arī, Leipzig.

STEINER, Heinrich (1865), Die Mu'taziliten oder die Freidenker im Islām. Ein Beitrag zur allgemeinen Culturgeschichte, Leipzig.

Stroumsa, Sarah (1989), Dāwūd ibn Marwān al-Muqammiṣ’s Twenty Chapters ('Ishrūn Maqāla), edited, translated and annotated, Leiden.

Stroumsa, Sarah (2007), «Soul-Searching at the dawn of Jewish Philosophy: A Hitherto Lost Fragment of al-Muqammaș's Twenty Chapters », Ginzei Qedem. Genizah Research Annual 13, p. 137*-61*.

Stroumsa, Sarah (2008), «The Muslim Context in Medieval Jewish Philosophy », Nadler-Rudavsky (eds.), The Cambridge History of Jewish Philosophy : From Antiquity through the Seventeenth Century, Cambridge, p. 39-59.

Thomas, David (2002), Early Muslim Polemic against Christianity. Abū 'İsā al-Warrāq's «Against the Incarnation », Cambridge.

Thomas, David (2004), «A Mu'tazilī Response to Christianity: Abū 'Alī al-Jubbā'̄ì's Attack on the Trinity and Incarnation », EBIED, Rifaat 
\& Teule, Herman (eds.), Studies on the Christian Arabic Heritage in Honour of Father Prof. Dr. Samir Khalil Samir, S.J. at the Occasion of his Sixty-Fifth Birthday, Leuven, p. 279-313.

Thomas, David (2007), « The Bible and the Kalām », Thomas, David (ed.), The Bible in Arab Christianity, Leiden, p. 175-91.

Thomas, David (2008), Christian Doctrines in Islamic Theology, Leiden.

Troupeau, Gérard (1962), Épître sur l'Unicité et la Trinité. Traité sur l'intellect et fragments sur l'âme de Mubyī al-Dīn al-Isfahān̄̄, texte arabe édité, traduit et commenté, Beyrouth.

Troupeau, Gérard (1995), Études sur le christianisme arabe au Moyen Age, Variorum, Aldershot.

VAJDA, Georges (1985), Al-Kitāb al-Muḅtawī de Yūsuf al-Bașīr. Texte, traduction et commentaire de G. Vajda, édité par Blumenthal, David R., Leiden.

WADI, A. (1997), Studio introduttivo su al-Mu'taman Ibn al- 'Assāl e la sua Summa dei Principi della Religione, Jérusalem-Le Caire.

WedEL, Gerhard (1987), Kitāb al-Ṭabbāḅ des Samaritaners Abū l-Hasan aș-Șūrī. Kritische Edition und kommentierte Übersetzung des ersten Teils, Thèse de Doctorat, Berlin.

WedEL, Gerhard (2007), « Mu'tazilitische Tendenzen im Kitāb al-Ṭabbāă des Samaritaners Abu 1-Hasan aș-Ṣūrī », AdANG, Camilla et al. (eds), A Common Rationality (voir plus haut), p. 349-75.

Wolfson, Harry Austryn (1979), Repercussions of the Kalam in Jewish Philosophy, Cambridge, Mass.

Zimmermann, Fritz W. (1985), « Kalām and the Greeks », Third International Colloquium on "From Jāhiliyya to Islam », Jérusalem, article non publié (nous remercions l'auteur de nous avoir communiqué son texte). 